\title{
INFLUENCE OF WET AND DRY CYCLE ON PROPERTIES OF MAGNESIA-BONDED WOOD-WOOL PANEL
}

\author{
Bin Na, Haiqing Wang, Tao Ding, Xiaoling Lu \\ Nanjing Forestry University \\ China \\ (Received January 20I9)
}

\begin{abstract}
In this paper, magnesia-bonded wood-wool panel was subjected to different times of wet and dry cycle to analyze their effects on the physical properties and the sound absorption property of the panel from macro and micro perspective. The results showed that with the increase of the wet and dry circle times, both MOE and thickness swelling decreased and the average absorption coefficient of the specimen increased.
\end{abstract}

KEYWORDS: Magnesia wood-wool panel, wet and dry cycle, sound absorption coefficient, thickness swelling, MOE.

\section{INTRODUCTION}

Magnesia-bonded wood wool panel (MWWP) is a panel made of wood-wool as reinforcing material bonded with hydration product after the reaction between magnesia (main content: $\mathrm{MgO}$ ) and $\mathrm{MgCl}_{2}$ solution (Na et al. 2012, 2013, 2014b, Wang et al. 2013a,b, Simatupang and Geimer 1990). The hydration product is indeed the magnesium oxychloride cement ( $\mathrm{Na}$ et al. 2012, 2013, 2014a, 2018). Magnesium oxychloride cement is a rigid gas cementing material, with advantages of fast condensation, high strength, low density, fire resistance etc. However, changes of temperature and humidity will greatly affect the surface stability of magnesium oxychloride cement, causing excessive moisture absorption, back to halogen, efflorescence and so on, and deteriorating physical and mechanical properties of magnesium oxychloride cement products.

Magnesium oxychloride cement is mainly composed of two alternate salt crystals (Zhu et al. 1994) of $5 \mathrm{Mg}(\mathrm{OH})_{2} \cdot \mathrm{MgCl}_{2} \cdot 8 \mathrm{H}_{2} \mathrm{O}$ and $3 \mathrm{Mg}(\mathrm{OH})_{2} \cdot \mathrm{MgCl}_{2} \cdot 8 \mathrm{H}_{2} \mathrm{O}$ produced by the reaction of magnesium oxide and magnesium chloride. The two complex salt crystals intertwined joined together with better crystalline rod or gel-like crystals. 5-phase, 3-phase crystals are fibrous, phase 5, showing the rod-shaped is comparatively thicker than 3-phase which presented as needle-like. In terms of crystal morphology (Matkovic and Yong 1973), $5 \mathrm{Mg}(\mathrm{OH})_{2} \cdot \mathrm{MgCl}_{2}$ - $8 \mathrm{H}_{2} \mathrm{O}$ is better than $3 \mathrm{Mg}(\mathrm{OH})_{2} \cdot \mathrm{MgCl}_{2} \cdot 8 \mathrm{H}_{2} \mathrm{O}$ and shows higher strength and stability. 
But when it is put in water or in a long-term high humidity environment, the 5-phase crystal will present a poor stability and break free $\mathrm{MgCl}_{2}$. However, studies have shown that in the high-temperature water vapor (Deng 2003, Deng and Zhang 1996), free $\mathrm{MgCl}_{2}$ can generate $\mathrm{Mg}(\mathrm{OH}) \mathrm{Cl}$ and precipitation, and thus effectively improve the MOC hygroscopic (Pan et al. 1984, Tong 1995). The crystal morphology of $\mathrm{Mg}(\mathrm{OH})_{2}$ is a large bulk crystal (Chen et al. 1996), showing a layered structure. So, when the proportion of $\mathrm{MgO}, \mathrm{MgCl}_{2}$ and $\mathrm{H}_{2} \mathrm{O}$ is appropriate, the 5 phases and $\mathrm{Mg}(\mathrm{OH})_{2}$ with high content and stability, magnesia-bonded wood-wool panel will have the highest intensity accordingly (Jiang et al. 2002). In addition, since the excess MgO can take further reaction to form $\mathrm{Mg}(\mathrm{OH})_{2}$, therefore a reasonable increase in moles of $\mathrm{H}_{2} \mathrm{O}$ will also help to enhance the panel strength.

\section{MATERIAL AND METHODS}

Since magnesia-bonded wood-wool panel is an new material, there is no standard on water sorption test of such material, considering the obvious impact of dry and wet cycles on its water resistance, so the experiment followed china aerated concrete wet-dry cycle test standard GB / T11975-1997 (China Standards Press 2014).

First, put the specimens in electric blast oven at $(60 \pm 5)^{\circ} \mathrm{C}$, and dried to constant mass; taken out and cooled $20 \mathrm{~min}$ at temperature of $(20 \pm 5)^{\circ} \mathrm{C}$; put the specimens in water at temperature of $(20 \pm 5)^{\circ} \mathrm{C}$; kept the specimen $30 \mathrm{~mm}$ below the water surface; removed the specimen $5 \mathrm{~min}$ later; put them in the air for $30 \mathrm{~min}$; after then kept the specimens in the oven at $(60 \pm 5)^{\circ} \mathrm{C}$ for $7 \mathrm{~h}$.

\section{RESULTS AND DISCUSSION}

Fig. 1 showed, after wet and dry treatment, the cross-sectional structure became obviously looser than before, and the wood-wool swelled. To further study changes of the crystalline phase after wet and dry treatment, SEM and XRD would be used in the following study.

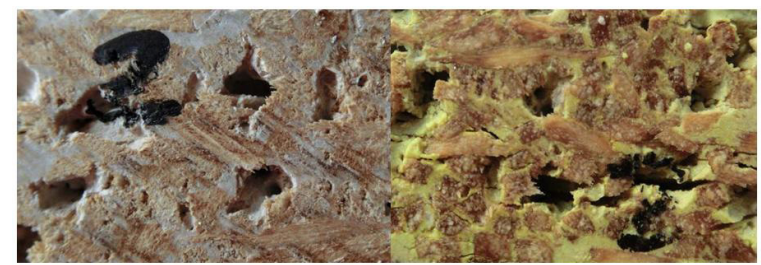

Fig. 1: Cross-sectional view of wood-wool panel before and after wet and dry treatment.

\section{XRD analyses}

Samples from magnesia wood-wool panels were prepared before /after wet and dry treatment respectively. Magnesium oxychloride cement was ground and those with the size of less than 200 mesh were kept. The microscopic analysis was made by X-ray diffraction (XRD) analyzer, the results were obtained as follows, in which: $1-\mathrm{MgCO}_{3}, 2-\mathrm{MgO}, 3-\mathrm{Mg}(\mathrm{OH})_{2}, 4-5 \mathrm{Mg}(\mathrm{OH})_{2}$ • $\mathrm{MgCl}_{2} \cdot 8 \mathrm{H}_{2} \mathrm{O}, 5-3 \mathrm{Mg}(\mathrm{OH})_{2} \cdot \mathrm{MgCl}_{2} \cdot 8 \mathrm{H}_{2} \mathrm{O}$. 

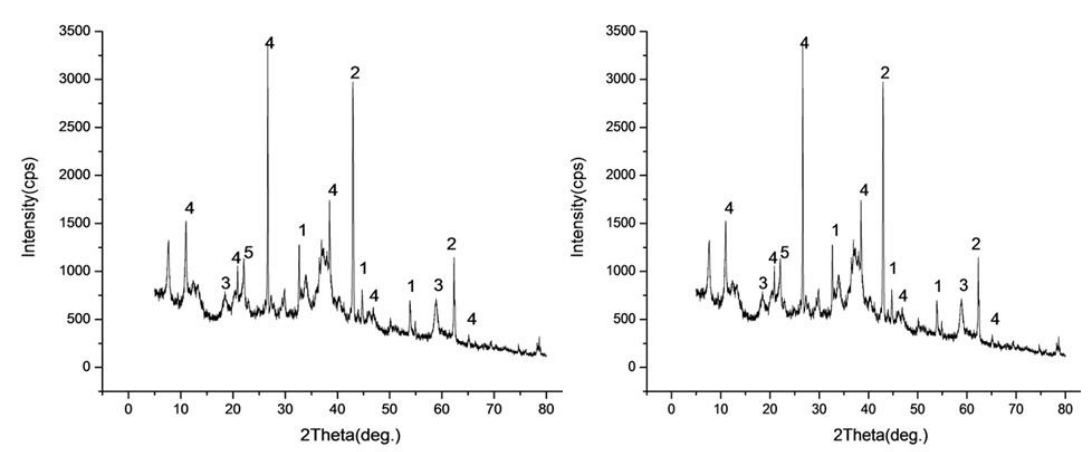

Fig. 2: XRD spectrum of untreated magnesium oxychloride cement panels with $n=0$.

Fig. 3: XRD spectrum of treated magnesium oxychloride cement panels with $n=2$.

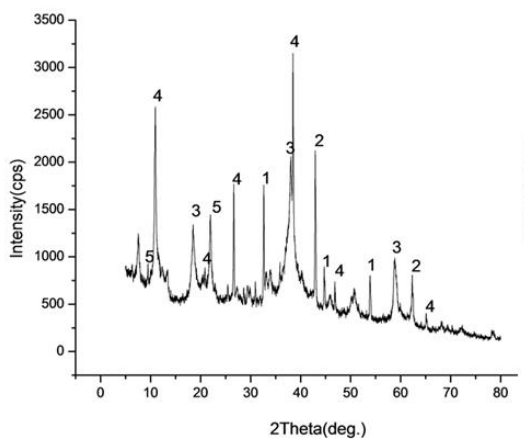

Fig. 4: XRD spectrum of treated magnesium oxychloride cement panels with $n=5$.

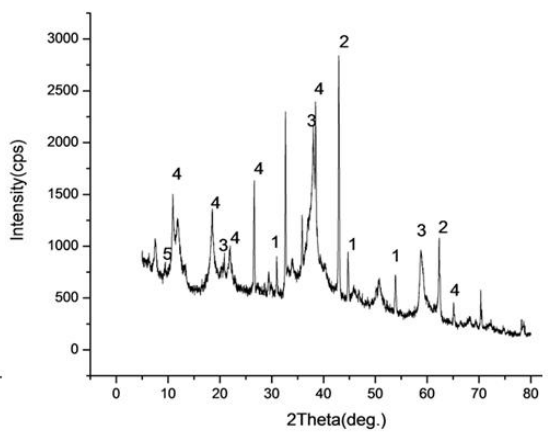

Fig. 5: XRD spectrum of magnesium oxychloride cement panels with $n=8$.

By comparing XRD spectra results of magnesium oxychloride cement under four states, it could be found that $\mathrm{MgCO}_{3}$ (magnesite), $\mathrm{MgO}$ (periclase), $\mathrm{Mg}(\mathrm{OH})_{2}$, five complex salt crystal phase and three-phase double salt crystals were the four main phases (Ji et al. 1995) existing in magnesium oxychloride cement with different times of wet-dry cycle process. By comparing Figs. 2, 3, 4, 5, it could be found that the intensity of diffraction peaks at the position of $2 \theta=38.48^{\circ}, 22.05^{\circ}$ and $10.99^{\circ}$ of the 5 -phase were greatly enhanced after 2 wet-dry cycles. With increase of the wet and dry cycle processing times increase, the peak intensity decreased, the peak shape gradually widened, which was especially obvious at $2 \theta=38.48^{\circ}$ in Fig. 4 and 5 comparing to Fig. 2 in which the peak appears thin and tall. The results showed that through 2 wet-dry cycles, 5 complex salt crystal phase had been changed with higher degree of crystallinity and higher content, but the rules of the crystal surface became poorer. With the increase of wetdry cycle process, the content of three complex salt crystal phase in magnesium oxycholoride cement decreased, and even close to disappear in some diffraction angle because 3-phase was unstable .The related studies showed when the molar ratio of $\mathrm{MgO}$ to $\mathrm{MgCl}_{2}$ is 4 or 5 , cement hydrates was unstable after flooding due to the dissolution and phase transformation would lead to decomposition of 3-phase hydrate (Guan and Ba 2009). In summary, 5 complex salt crystal 
phase (Xia et al. 1994) in magnesium oxychloride cement increased gradually with increase of the wet and dry cycle $\mathrm{p}$ times, The crystal grown no better than those were not suffered the wet and dry cycle treatment. This was one of main reasons that the strength of panel was decreased with increase of wet and dry cycle times.

\section{SEM analyses}

Specimens were taken from magnesium oxychloride cements with different times of wet-dry cycle process, and analyzed by scanning electron microscope (SEM). The results of specimens with $\mathrm{n}=0,2,5,8$ (times of wet and dry cycle) are shown as follows.

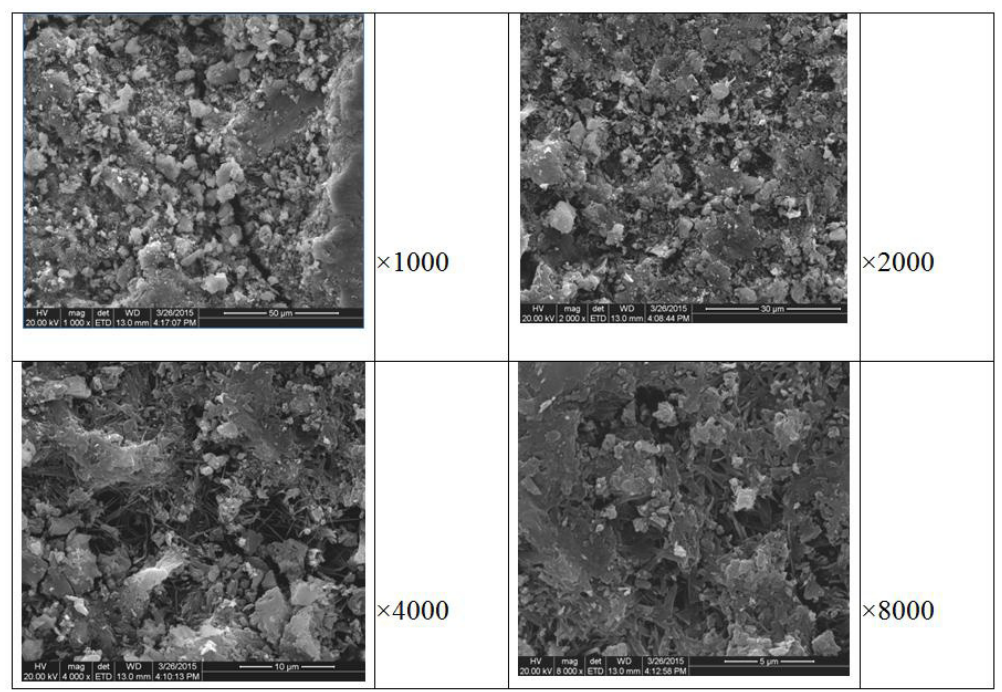

Fig. 6: SEM micrograph of magnesium wood wool panels with $n=0$.

Fig. 6 showed that the surface morphology of magnesium oxychloride cement with $\mathrm{n}=0$ presented colloidal showing topography, mainly formed by layered, rod-shaped and needleshaped structure. 5 phasewas rod-like; t 3 phase was needle-like and $\mathrm{Mg}(\mathrm{OH})_{2}$ is bulk crystal with layered structure (Shuxing 2011). The strength and stability of a 5-phase crystals were better than $\mathrm{Mg}(\mathrm{OH})_{2}$ crystal phase, thus illustrated that there were lots of 3-phase, 5-phase complex salt crystals and $\mathrm{Mg}(\mathrm{OH})_{2}$ crystalline phase. So under normal circumstances, the higher the content of 5-phase crystals were, the greater the intensity of magnesium oxychloride cement was. 
Comparing Fig. 6 and Fig. 7, it can be found that the layered structure on the surface of magnesium oxychloride cement surface reduced after 2 times wet and dry cycles. That means, that the $\mathrm{Mg}(\mathrm{OH})_{2}$ phase was reduced. Comparing picture of $\times 8000$, it could be found when the pore diameter increased until that the cement structure became relatively loose, but it also made the material porosity increase, thus the sound absorption property of the panel was increased.

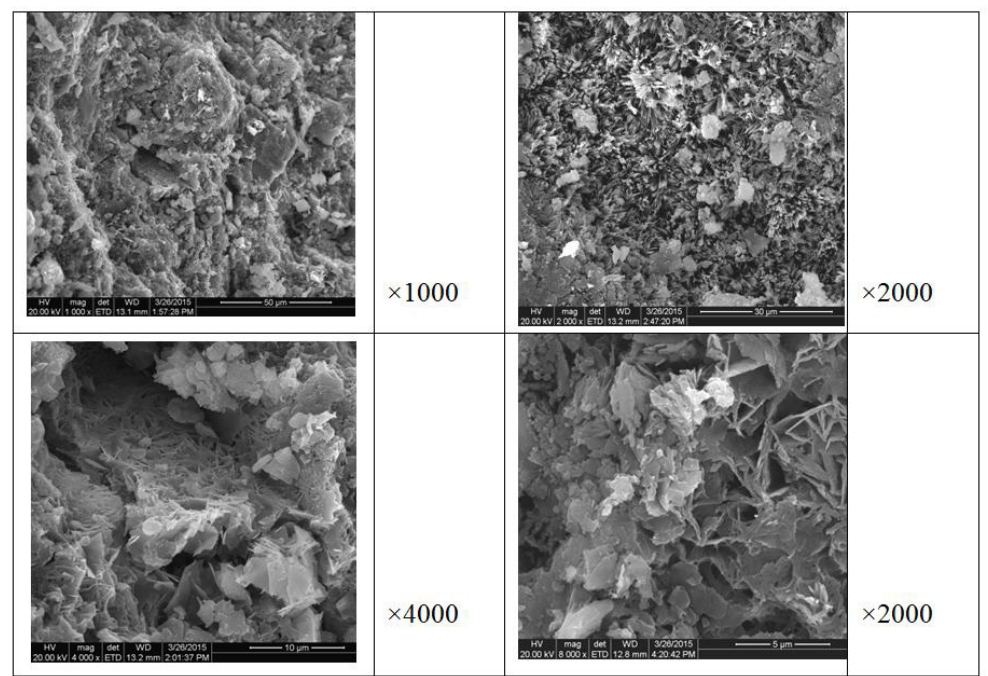

Fig. 7: SEM micrograph of magnesium wood wool panels with $n=2$.

Comparing 2000 times photos of Fig. 6, 7, and 8, it could be found that the layered structure on the surface of magnesium oxychloride cement surface was significantly reduced, that meant, the $\mathrm{Mg}(\mathrm{OH})_{2}$ phase was greatly reduced, but the 5-phase crystal rod increased obviously which should have improved the physical strength of the panel.

However, comparing 2000 times and 8000 times photos in Figs. 6 and 8, the following results were found: 5 -phase crystal growth basically in holes or voids, and grow radially from the hole edge to centre, or radiate outwardly from the pores. The $\mathrm{MgCl}_{2}$ solution and $\mathrm{MgO}$ particles can easily fill holes and voids, and interaction occurred therein, providing sufficient space to facilitate the growth of 5 phase. This kind of radial crystal in holes had no contribution to the strength of magnesium oxychloride cement because this radial crystal did not form the network crystal structure. On the contrary, the existence of such holes reduced the strength of magnesia cement. 


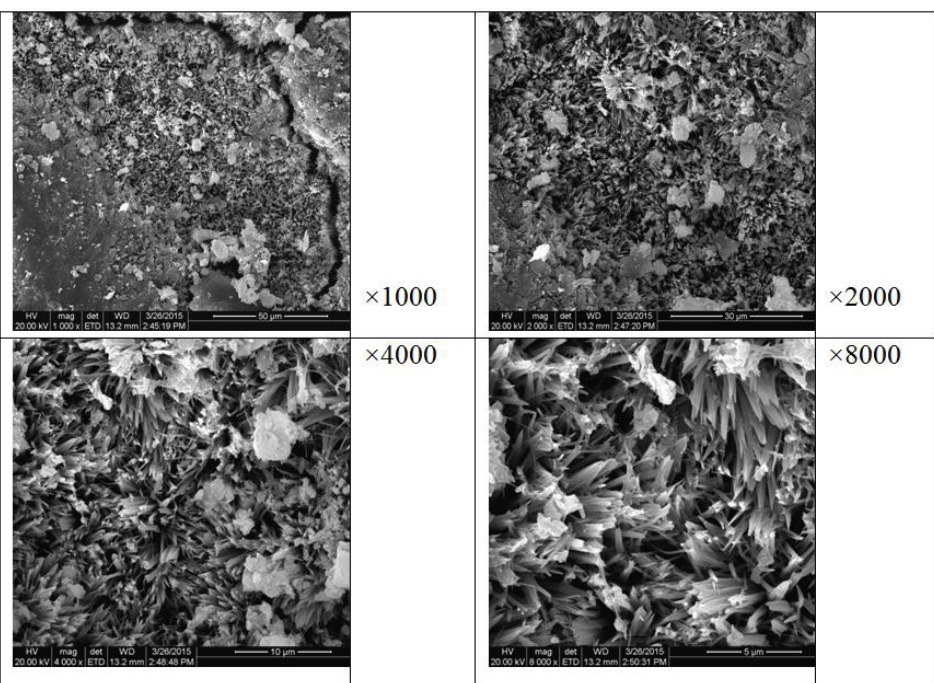

Fig. 8: SEM micrograph of magnesium wood wool panels with $n=5$.

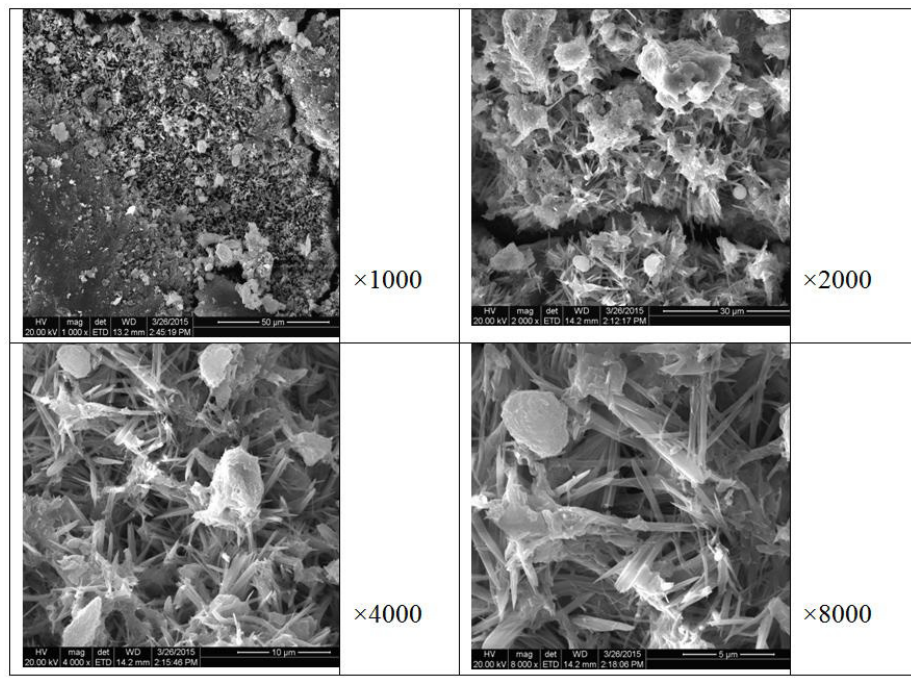

Fig. 9: SEM micrograph of magnesium wood wool panels with $n=8$.

Comparing 4000 times photos of Fig. 8 and Fig. 9, it could be found that in both photos, layered structure became rare, but the later structure was obviously looser than the former. Hardened cement formed by composite-magnesia-cement materials was similar to other kinds of hardened-bodies. The formation of sufficient stable hydrates and the well intersection crossed each other, and a continuous, dense crystalline structure of cement in the whole space, these two were the prerequisites ensuring the cement's physical strength. The loose structure of 5 phase could not cross over with each other, so even the high 5 phase content could not bring high 
strength, wood moisture expansion which led to hardened-body cracking is another important reason (Tu 1996).

\section{Analysis of thickness swelling}

From Fig. 10, it could be found that, the longer the panel was soaked, the higher the panel thickness swelling would be. This showed that the water resistance property of magnesium oxychloride cement was poor. Combining the XRD and SEM results, the following reasons could be found: on the one hand, the magnesium oxychloride cement hydration products were unstable in water, especially the 3-phase, which could be dissolved in water. The other reason was the wood-wool's property of moisture absorption. When the wood-wool's expansion reached a certain level, the expansion stress would exceed the MOC's internal stress, and result in the destruction of the internal structure of magnesium oxychloride cement, and the decrease of MOC's physical and mechanical properties, thereby reducing the binding force to the wood fiber. Thus the improvement of the panel's water resistance heavily depended on the improvement of magnesium oxychloride cement's water resistance.

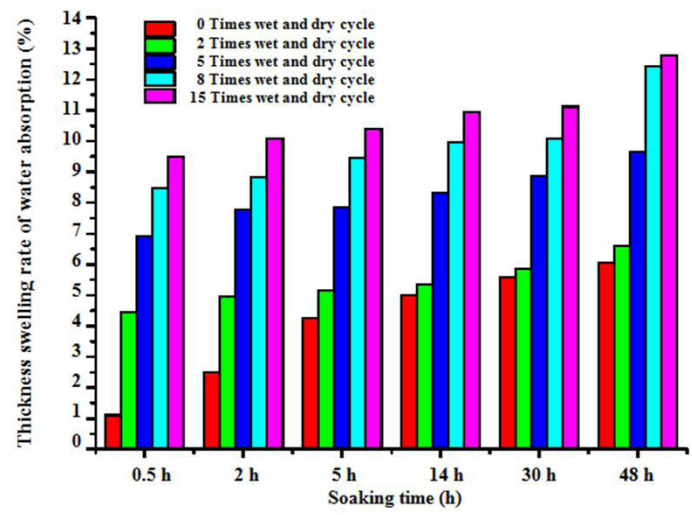

Fig. 10: Effects of wet and dry cycles on thickness swelling.

Further analyse showed that the specimen had not been handled with wet and dry cycles. Its thickness swelling ratio increased rapidly at the initial five hours, after which, the value rose slowly, while this value of those specimen being handled was relatively smaller with time going even their thickness swelling value was larger than the former. This was because the three-phase hydrates hydrolyzed in soaking process, then in the drying process, those active $\mathrm{MgO}$ which did not react would combine with free $\mathrm{H}_{2} \mathrm{O}$ to generate $\mathrm{Mg}(\mathrm{OH})_{2}$ crystals. With the increase of time, the content of 5 phase increased which was relatively stable than 3 phase, so the following soaking process had little effect on its thickness swelling ratio. Thus, the impact of wet and dry cycles on the panel's thickness swelling ratio came mainly from the wood wool's hygroscopic expansion and the decomposition of some hydration products in the cement.

\section{Mechanical performance analysis}

Fig. 11 showed that with the increase of wet and dry cycles, the panel showed a nonlinear decrease of MOE. The slope of the curve with $n \leq 2$ was significantly greater than $2<n \leq 15$, which indicated that MOE of the panel sharply declined after 2 cycles, and with increase of the circle time, the rate of decline decreased. This change trend was consistent with the change of 
thickness swelling, which also indicating that the poor water resistance of magnesium oxychloride cement was the main reason leading to a sharp decline in the MOE of the panel after wet and dry circle. The following relationship between the plate elastic modulus $(\mathrm{Eb})$ and the times of wet and dry cycle (n) was established by ORIGIN nonlinear fitting:

$$
E_{\mathrm{b}}=51.69429 n^{2}-559.37371 n+1633.856
$$

where: $\quad E_{b}$ - elastic modulus, $(\mathrm{MPa})$, $n$ - times of wet and dry cycle, $\mathrm{n} \leq 15$.

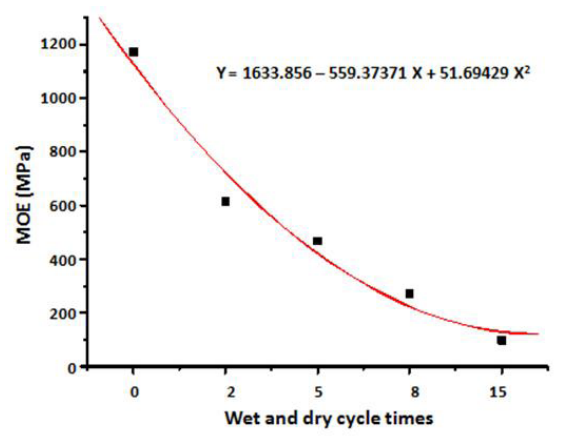

Fig. 11: Effects of wet and dry cycles on $M O E$.

Fitting results are analyzed as follows. Tab. 1 showed the correlation coefficients between $\mathrm{Eb}$ and $n=0.972$, indicating high correlation between them. At the same time, the table showed the value of standard deviation and fitting deviation were big because of the limited times of wet and dry circle. But in the actual use, the requirements about MOE of the panel itself was not high, and furthermore, MOE of the panel was able to meet the standard requirements for wood-wool panel even with $n=8$. So the simulation results were applicable for a rough estimate of MOE of the panel value with $\mathrm{n} \leq 15$ in engineering application.

Tab. 1: Analysis of fitting results between $M O E$ and wet and dry cycles.

\begin{tabular}{|c|c|c|c|}
\hline \multicolumn{4}{|c|}{$Y=A+B * X$} \\
\hline Parameter & Results & Deviation & \\
\hline A & 1633.856 & 208.429 & \\
\hline $\mathrm{B}$ & -559.371 & 158.837 & \\
\hline Correlation coefficient $\mathrm{R}$ & $\mathrm{SD}$ & Number of parameters $(\mathrm{N})$ & $\mathrm{P}$ \\
\hline 0.972 & 97.181 & 5 & $<0.027$ \\
\hline
\end{tabular}

\section{Analysis of sound absorption properties}

A large number of experimental specimens were used, and the following four typical sound absorption characteristics were found. 


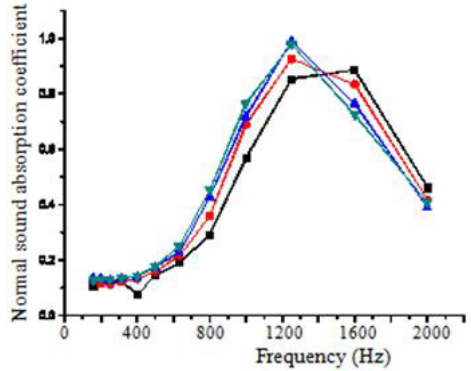

(a)

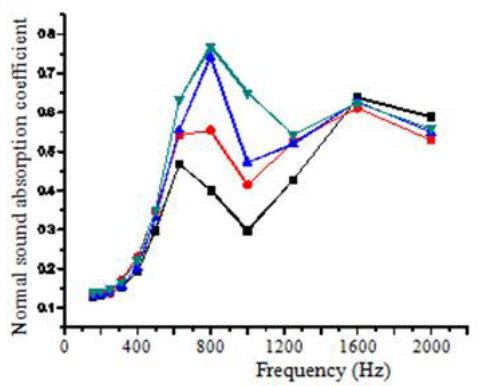

(c)

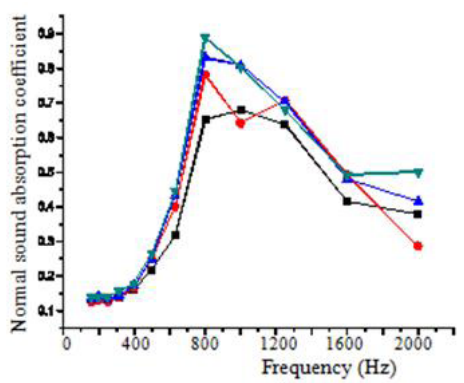

(b)

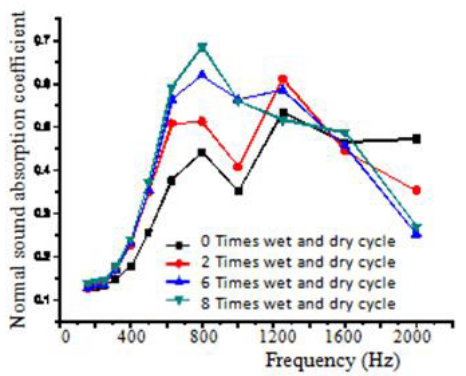

(d)

Fig. 12: Four typical sound absorption properties.

In Fig. 12a: (1) the peak value of absorption coefficient before/after wet and dry cycles were at $f=1600 \mathrm{~Hz}, f=1200 \mathrm{~Hz}$ respectively, that was, after wet-dry cycle the panel's sound coefficient peak value shifted to lower frequency; (2) the panel's sound absorption performance was poor when $\mathrm{f} \leq 600 \mathrm{~Hz}$.

In Fig. 12b: (1) both the peak value of absorption coefficient before/after wet and dry cycles were at $f=800 \mathrm{~Hz}$; (2) with the increase of $\mathrm{n}$, sound absorption coefficients at the stage of $f \leq 800 \mathrm{~Hz}$ continued to improve which was less clear at high frequencies.

In Fig. 12c: (1) there were two peak values of absorption coefficient before /after wet and dry cycles, and the first peak value transferred from $600 \mathrm{~Hz}$ to $800 \mathrm{~Hz}$ after wet and dry circles. Both the valley values appeared at $1000 \mathrm{~Hz}$; (2) the panel's sound absorption performance was poor when $f \leq 600 \mathrm{~Hz}$. (3) before the stage of $\mathrm{f} \leq 1000 \mathrm{~Hz}$, the absorption coefficient increased substantially with the increase of $n$.

In Fig. 12d: (1) there were two peak values of absorption coefficient before/after wet and dry cycles, and the first peak value transferred from $800 \mathrm{~Hz}$ to $1250 \mathrm{~Hz}$ after wet and dry circles; (2) the panel's sound absorption coefficients increased with the increase of $n$, and the value decreases rapidly when $f=2000 \mathrm{~Hz}$.

The following two points were reached by comparing this four figures: (1) poor low frequency sound absorption performance were presented with the increase of $n$, but the trend was not apparent at the frequency channel of high frequency; (2) The main difference between the four typical sound absorption characteristic diagrams was that the first two contains only one peak while the latter two peaks. 
Mechanism analysis: during the process of wet and dry cycle, the crystal hydration product was hydrolyzed and generated $\mathrm{Mg}(\mathrm{OH})_{2}$ when the panel was soaked in water because of its high solubility in water, and the $\mathrm{Mg}(\mathrm{OH})_{2}$ was a bulk crystal (Yang 1999) with layered structure and hardened body much lower in intensity which was composed of the rod-like gel 5-phase crystals and the sharp needle-shaped 3-phase crystals. On the other hand, wood-wool's moisture expansion would result in swelling stress, when 5-phase and 3-phase crystals dissolved, the strength of the panel was lower than the swelling stress, then the panel's deformation was produced, thus the panel's strength decreased rapidly. Therefore, the strength loss of magnesium oxychloride cement wood-wool panel was not only due to the physical action of water, but also mainly led by the solubility characteristics of 5-phase and 3-phase crystals and wood-wool's swelling stress (Delany and Bazley 1970).

\section{CONCLUSIONS}

This paper examined effect of wet and dry cycle on thickness swelling, MOE and normal sound absorption coefficient of the panel from the macro and micro perspective and explored oxychloride changes of microstructure of magnesium cement hydration product during the wet and dry cycle process. The following conclusions were shown as follows:

(1) After the wet and dry cycles, MOE and thickness swelling of the specimens decreased, and with the increase of wet and dry cycles, the decline decreased; the average absorption coefficient of the specimen increased, mainly due to the increased plate thickness and magnesium oxychloride cement in 5-phase crystal structure changes, the porosity increased. The absorption coefficient of the plate were particularly sensitive to the microstructure of the panel, But on the whole, the low-frequency sound absorption property of magnesia-bonded wood-wool panel was poor. At around $1000 \mathrm{~Hz}$, sound absorption property of the panel was the best which applied to sound insulation for civil building.

(2) For the magnesium oxychloride cement before/after wet-dry cycles, the ARD and SEM results showed that: with the increase of wet and dry cycles, magnesium oxychloride cement $\mathrm{Mg}(\mathrm{OH})_{2}$ crystals gradually reduced, and finally almost completely disappeared, hydrolysis of 3-phase double salt crystals occurred in the soaking process, the five-phase double salt crystals gradually increased. However, after the wet and dry cycles, disappear of $\mathrm{Mg}(\mathrm{OH})_{2}$ in the panel crystals of ledto pore diameter in magnesium oxychloride cement larger, the crystal structure of a 5-phase complex salt crystals from the original high strength and gelled into a rod from gap around the radial centre of the structure to improve the strength of the panel, which led to an increase in 5-phase complex salt crystals, but the physical strength of the panel was reduced.

\section{ACKNOWLEDGEMENTS}

This study was funded by northern Jiangsu scientific and technological development plan of China (BC2012417). The authors would also like to thank the support of the Priority Academic Program Development of Jiangsu Higher Education Institutions of China. 


\section{REFERENCES}

1. China Building Material Academy, 2003: Green building material and technologies reaching it. Chemical Industry Press, Beijing.

2. Chen, X., Cao, J., Liu, Y., 1996: Looking into the ways of solving water tolerant behaviour of magnesite materials. Hunan Chemical Industry 26(3): 34-37.

3. Deng, D., 2003: The mechanism for soluble phosphates to improve the water resistance of magnesium oxychloride cement. Cement and Concrete Research 33 (9): 1311-1317.

4. Deng, D., Zhang, C., 1996: Theoretical mechanism of hygroscopicity of magnesium oxychloride cement and technical methods to lower it. Neo-Building Materials (10): 24-27.

5. Delany, M.E., Bazley, E.N., 1970: Acoustic properties of fibrous absorbent materials. Applied Acoustics (3): 105-116.

6. Guan, F., Ba, H., 2009: Study on phase stability of magnesium oxychloride cement. Journal of Harbin Engineering University 30(11): 1213-1218 (in Chinese).

7. China Standards Press, 2014: Standard complication of cement products in building materials. China Concrete and Cement Products (2): 43 (in Chinese).

8. Ji, Y., Wu, Z., Zhang, F., 1995: Influence of the additive on the microstructure and performance of the new water-resisting magnesium cement. Journal of Inorganic Materials 10(2): 241-247.

9. Jiang, J., Luo, Y., Lan, X., 2002: Novel thermal insulation and soundproofing building material. Chemical Industry Press, Beijing.

10. Matkovic, B., Yong, J.F., 1973: Microstructure of magnesium oxychloride cements. Natural Physical Science 246: 79-80.

11. Na, B., Wang, Z., Wang, H., Lu, X., 2012: Study on improvement of hygroscopicity property of low density magnesia-bonded wood-wool panel. Journal of Building Materials 15(5): 660-664 (in Chinese).

12. Na, B., Zhao, Y., Wang, Z., Lu, X., 2013: Effects of additives on mechanical property and hygroscopicity property of low density magnesia-bonded wood wool-panel. Journal of Northwest Forestry University 28(2): 168-172 (in Chinese).

13. Na, B., Wang, Z., Wang, H., Ding T., Lu, X., 2014a: Study on hydration mechanism of low density magnesia-bonded wood wool panel. Wood Research 59(1): 137-148.

14. Na, B., Wang, Z., Wang, H., Lu, X., 2014b: Wood-cement compatibility review. Wood Research 59(5): 813-826.

15. Na, B., Wang, H., Ding, T., Lu, X., 2018: Study on factors affecting the sound absorption property of magnesia-bonded wood wool panel. Wood Research 63(4): 617-624.

16. Pan, G., Zhao, Z., Liu, Ch., 1984: Chemical reactive manual. Liaoning People's Publishing House 5: 26-30 (in Chinese).

17. Simatupang, M.H., Geimer, R.L., 1990: Inorganic binder for wood composites: feasibility and limitations. In: Wood Adhesives 1990. Wisconsin, 8 pp.

18. Shuxing, J., 2011: Study on hydration phase and microscopic characteristic of the composite magnesium oxychloride cement. Non-Metallic Mines 34(5): 42-44 (in Chinese).

19. Tu, P., 1996: Application of water in magnesium oxychloride cementitious material. China Building Materials (2): 42-43 (in Chinese).

20. Tong, Y., 1995: Study on factors affecting the water resistance property of magnesium oxychloride cement by orthogonal experiment. New Building Materials (2): 42-43 (in Chinese). 
21. Xia, S., Wang, J., Huang, J., Chen, R., 1994: Influence of additives on dimensional stability of magnesium oxychloride cement. Journal of Salt \& Chemical Industry 23(6): 18-22.

22. Yang, S., 1999: Thermal insulation and soundproofing building material. China Planning Press, Beijing.

23. Wang, Z., Sun, D., Chen, X., Zhao, X., Na, B., Lu, X., 2013a: Study on the sound absorption and thermal conductivity properties of low density magnesia-bonded wood wool panel. Journal of Southwest Forestry University 33(3): 97-101.

24. Wang, Z., Sun, D., Chen, X., LiQ., Liu H.., 2013b: Steam-pressing mechanism of low density magnesia-bonded wood wool panel. Journal of Northwest Forestry University 28(6): 165-168.

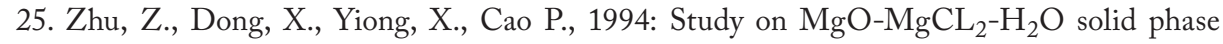
system. Journal of Shandong Institute of building materials 8(1): 8-18.

*Bin Na, Haiqing Wang, Tao Ding, Xiaoling Lu

College of Materials Science and Engineering

Nanjing Forestry University

NANJING, 2 IOO37

CHINA

*Corresponding author: nabin8691@126.com 